\title{
Reina Rosario,
}

\section{Identidades de la población de origen jamaiquino en el Caribe costarricense (segunda mitad del siglo XX)}

\section{Mu-Kien Adriana Sang Ben ${ }^{1}$}

Recepción: 25 de setiembre de 2016 / Aprobación: 3 de octubre de 2016

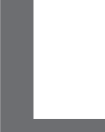

a introducción del libro comienza con una afirmación de la autora, quien propone que lo más interesante de la comunidad de origen jamaiquino en Costa Rica es que ha logrado, desde el siglo XIX, "mantener, recrear y reproducir discursos (ser negro frente a un mundo de blancos) sobre identidad étnica (caribeña-negra-africana) en una sociedad que históricamente se asume como blanca, descendiente de europeos" (Rosario, 2015, p. 18). Es por esta impronta multicultural y multiétnica que la investigadora decide colocar en la introducción, la definición de los conceptos empleados tales como: negro, afrocaribeño, afrodescendiente, afrocostarricense, entre otros.

Para entender las complejidades de la conformación de las identidades en cuestión, Rosario hace uso del concepto de "Comunidades Imaginadas" de Benedict Anderson, en el cual se afirma que la construcción de la identidad nacional, que ha prevalecido en América Latina, es la llamada primordialista y tradicionalista, en la cual los conceptos de nación y nacionalidad son concebidos como herencia colonial. Para Anderson, como defensa de la perspectiva constructivista e invencionista, la identidad y la nación deben ser vistas como comunidades imaginadas, limitadas y soberanas. En Costa Rica, dice la autora, "hasta hace poco, predominaba la tendencia a considerar la nación como algo ya constituido para finales de la colonia, o latente, que se manifestaba a través del siglo XIX" (p. 28). Con la utilización crítica de estos conceptos, la autora expresa una de sus principales líneas argumentativas: "el presente estudio asume la visión invencionista con la cual pretendemos mostrar cómo, en el proceso de invención de la nación costarricense, se fueron segregando e invisibilizando las minorías étnicas y se desconocen sus aportes a la cultura costarricense" (p. 32).

Basándose en las ideas de Anthony Smith, Rosario defiende la existencia de una muy estrecha relación entre los conceptos de etnia y nación, ya que,

1 Dominicana. Doctora en Historia y Civilización por la Escuela de Altos Estudios de Ciencias Sociales de París, Francia. Presidenta de la Academia Dominicana de la Historia. Docente en el Instituto Tecnológico de Santo Domingo (INTEC), República Dominicana. Correo electrónico: sangbenmukien@gmail.com 
afirma la autora, tanto la nación como la comunidad étnica son comunidades de mitos y recuerdos colectivos. Lo usual, de acuerdo con Rosario, es que exista una confusión en la mayoría de la gente acerca de los dos conceptos. La comunidad étnica, dice, carece de algunos atributos que sí tienen las naciones. Una de ellas es el territorio; otro elemento clave es la existencia de códigos legales comunes.

El libro consta de cuatro capítulos. El primero, titulado "Orígenes de la comunidad jamaiquina del Caribe costarricense: los primeros discursos identitarios (1872-1950)", señala que el interés de los gobiernos de Costa Rica por la región del Caribe comenzó en el siglo XIX, iniciándose en el gobierno de Juan Rafael Mora, en 1852, y continuando con los gobiernos de Jesús Jiménez Zamora, José María Castro Madriz y Bruno Carranza. Durante varias décadas dictaron decretos que habilitaban el puerto de Limón, cuando todavía era un lugar abandonado. Pero no fue sino hasta finales del siglo XIX, durante el período de Tomás Guardia, cuando se mostró el interés manifiesto, "no con el fin de integrar la población indígena al Estado-Nación, sino con el propósito de construir un ferrocarril para comercializar la producción cafetalera del Valle Central hacia Europa, que se efectuaba por el Océano Pacífico" (p. 84). Así, en 1871, el entonces presidente Tomás Guardia firmó un contrato para la construcción de un tramo de ferrocarril de 150 kilómetros con el empresario estadounidense Henry Meiggs, que en principio iba del puerto de Limón hacia el interior.

Cuando se conectó, dice la autora, la construcción del ferrocarril con el negocio del banano, sumado al creciente capital norteamericano, se produjo una transformación profunda de la economía de la región y cambios profundos a nivel demográfico. La creciente mano de obra demandada no podía ser suplida por la población nativa, por esta razón se trajeron trabajadores de muchos lugares, a saber:

Las condiciones de vida y de trabajo en el Caribe costarricense fueron duras y peligrosas, especialmente en los primeros años cuando no había viviendas, transporte, agua potable y el área era inhóspita. Durante ese período llegaron inmigrantes alemanes, belgas, suizos e ingleses. Pero muy pronto los costos económicos obligaron a contratar a otra población menos demandante y más barata como los chinos, jamaiquinos, curazaleños, italianos, culíes procedentes de la India y centroamericanos, entre otros (p. 84).

Se repetía la misma historia del Caribe insular del siglo XIX, del Gran Caribe: el desarrollo del capital requería de mano de obra asalariada, pero en realidad eran condiciones laborales prácticamente esclavistas. La autora afirma que, a finales del siglo XIX, los empresarios se dieron cuenta de que la mano de obra de los jamaiquinos era la más beneficiosa: hablaban inglés, tenían experiencia en el cultivo del banano y en Jamaica la población quería salir de la gran crisis económica que existía en su tierra, tres condiciones que se combinaron y produjeron un fenómeno único en Costa Rica. Se calcula que entre 1891 y 1911 llegaron a Costa Rica unos 43438 jamaiquinos. En el año 
1927, solo en Limón había 19136 jamaiquinos. Ahí comienza a conformarse un imaginario diferente de una población marginada no solo económica y socialmente sino también desde el punto de vista geográfico.

La historiadora destaca que el Estado de Costa Rica entregó la región completamente al enclave bananero y abandonó a su suerte a los trabajadores. La compañía bananera, la United Fruit Company (UFCO), se debía encargar de la vida de los trabajadores en todos los órdenes. Las condiciones eran tan difíciles que la utopía del regreso se convirtió en la esperanza de los jamaiquinos. La UFCO era la dueña absoluta de la producción de banano, del transporte ferroviario, la comercialización y de todos los demás aspectos de la producción. A partir de esa realidad, los jamaiquinos comenzaron a recrear su propia cultura. La resistencia silente de los marginados, de los pobres, fue alimentando su ser colectivo. No solo valoró su cultura, sino que estableció las diferencias con los "otros", entiéndase los costarricenses, los norteamericanos, los indígenas, los negros francófonos, los centroamericanos y los chinos.

El segundo capítulo que lleva por título "Contexto sociopolítico de la provincia de Limón en la segunda mitad del siglo XX" nos sitúa en el espacio físico de esta historia. Es una precisa radiografía de la provincia, en la que, apelando a la perspectiva histórica, la autora explica algunos de los elementos que presenta en su descripción. Rosario documenta el relato con fotografías y cuadros. En el tercer capítulo titulado "Desde la ciudadanía a la identidad negociada. 19501970", como bien afirma la autora, a partir de la mitad del siglo XX, se produjo un cambio radical en las relaciones del Estado con la provincia de Limón, pero sobre todo, con la población de origen jamaiquino. El Estado comenzó a ejercer control político sobre la región, situación novedosa, ya que nunca antes había estado integrada al resto de la nación. Con la llegada de José Figueres Ferrer al poder, en 1948, la población de origen jamaiquino clamó por su incorporación social, política y económica a la sociedad costarricense. El nuevo presidente fue clave para ese cambio.

Sin embargo, a pesar de los intentos por integrar a la región al resto de país, la discriminación y las prácticas discriminatorias no se podían eliminar tan fácilmente. Un esfuerzo en este sentido fue la Ley No. 5360 de 1973, la cual prohibía las restricciones de migración fundadas en elementos raciales². De esta manera, la legislación del país se ponía a tono con la Convención Internacional sobre la Eliminación de todas las Formas de Discriminación Racial, suscrita por Costa Rica, en $1966^{3}$. Para sustentar sus argumentos, la investigadora leyó, citó y organizó en un cuadro, con todos los discursos de

2 Costa Rica. Ley No. 5360 de 1973, Prohíbe restricciones a inmigración por raza, 1973. Recuperado de http://www.refworld.org/docid/46d6b2a92.html

3 ONU. Convención Internacional sobre la Eliminación de todas las Formas de Discriminación Racial, adoptada y abierta a la firma y ratificación por la Asamblea General en su resolución 2106 A (XX), de 21 de diciembre de 1965. Recuperado de http://www.ohchr.org/SP/Professionallnterest/Pages/CERD.aspx 
los presidentes de Costa Rica en materia racial desde 1949, cuando Figueres asumió el poder, hasta 1966 cuando José Joaquín Trejos tomó juramento.

En ese proceso de cambio, por primera vez en la historia de Costa Rica, un negro de origen jamaiquino, Alex Curling, fue designado como Jefe de Acción Política del Partido de Liberación Nacional (PLN) para el cantón de Siquirres. En la Convención del PLN para escoger a los candidatos a la Asamblea Legislativa, Alex Curling fue postulado, a pesar de la oposición y resistencia que hubo dentro las mismas filas del partido. Por primera vez en las elecciones de 1953, dos negros fueron colocados en las papeletas y elegidos: Alex Curling fue electo como diputado suplente y Stanley Britton fue escogido como segundo puesto en la papeleta municipal. A partir de ese momento, propone la historiadora, en el PLN se eligió siempre un candidato negro para la provincia de Limón. Tiempo después, los demás partidos incluyeron en sus listas de candidatos a posiciones legislativas a miembros de la comunidad de origen jamaiquino.

Sobre el tema cultural, Rosario afirma que, en la comunidad de origen jamaiquino, como ocurrió en varias islas del Caribe durante la migración cocola en los primeros años del siglo XX, se puede afirmar que el inglés fue la lengua nativa, aunque poco a poco se sumó al español, que era la lengua dominante. Aferrarse al idioma de los ancestros era una forma de vincularse a su propia identidad, ser ellos y, ser sobre todo, diferente a los Otros. Igualmente, en Costa Rica, como sucedió en otras regiones del Caribe, las poblaciones negras migrantes se aferraron a sus creencias; se desarrollaron las logias. Se calcula que, para la década de 1950, existían en Limón más de 20 logias y asociaciones fraternas y benevolentes; otra forma de mantener su identidad y compartir sus valores. Eran secretas, pero hacían sus bailes y desfiles públicos, mostrando sus elementos distintivos como etnia.

La música también fue una expresión de su propia identidad, como el calipso limonense, que, a juicio de los estudiosos, tiene una clara influencia de la música jamaiquina y de otros lugares del Caribe. En ese marco, se inscribe el carnaval limonense, el cual, dice Rosario, es una obra "maestra de la historia social universal" (p. 286). El carnaval limonense existe desde los primeros años del siglo XX, según los estudiosos. Hay rastros de celebraciones antes de 1949, pero se afianzó a partir de ese año tan significativo para la región.

La autora concluye el tercer capítulo con una pregunta: ¿soy negro o soy costarricense? (p. 295) ¡He ahí el dilema! Esta fue una duda existencial que se agigantó con la historia de segregación y explotación de esas poblaciones. Al final, debieron asumir la ciudadanía; la identidad grupal era otra cosa. Como lo dijo Curling en una sesión de la Asamblea Legislativa: "Me siento orgulloso de decir que soy costarricense, solo costarricense" (p. 297). Esta decisión permitió que el grado de inserción política fuera constante y ascendente. Estos 30 años, como bien dice la investigadora, tienen que ser analizados en el 
contexto internacional: Guerra Fría, luchas de los movimientos revolucionarios en América Latina y, sobre todo, lucha de los negros norteamericanos en búsqueda de igualdad. Los nombres del Che Guevara, por un lado, y Malcom X, por el otro, resonaban en los grupos del mundo, y, por supuesto, en el Caribe como ejemplos de luchas por igualdades.

El libro está muy bien escrito y documentado (las fuentes utilizadas fueron tomadas del Archivo de la Asamblea Legislativa, el Archivo Nacional de Costa Rica, el Archivo de la Municipalidad de Limón; Ios Informes de la Gobernación de la provincia de Limón; la Biblioteca del Ministerio de Relaciones Exteriores y los Archivos de Japdeva; discursos, periódicos, informes, cartas, censos, fotografías; además de fuentes orales). A mi juicio constituye un verdadero aporte al conocimiento de las poblaciones excluidas, minorías caribeñas, mal denominadas "minorías", porque numéricamente son mucho más.

A pesar de que valoro de gran manera la obra por sus aportes, tengo algunas observaciones críticas:

La cronología. Como historiadores, en nuestro afán por tratar un tema, a veces no respetamos la cronología. Creo que la mejor manera de mantener el discurso es respetando el proceso según el paso del tiempo. A veces, en el texto se está refiriendo al siglo XIX, cuando de repente se sigue leyendo y sin preámbulos se comienza a hablar del siglo XX. El tercer capítulo salta de la década de 1950 a la de 1990 y los primeros años del 2000, a veces sin pausa, con prisas y sin explicaciones claras. Pienso que en el retrato del Limón debió respetarse la cronología de tal manera que la persona lectora pudiera seguir la transformación de la localidad en su paso por el tiempo. A veces olvidamos que quien lee es alguien que se adentra en el lugar que se describe, que recorre las calles, las casas y las personas que la habitan. El lector recorre los lugares a través de las palabras y, como testigo del tiempo, no puede recibir la sorpresa de los saltos, casi abismos, en los tiempos. Sin embargo, la observación no desmerita el trabajo y el objetivo en el capítulo se entendió perfectamente.

Sesgo ideológico. El texto, visto desde una perspectiva historiográfica pura, para decirlo de alguna manera, presenta un desbalance ideológico. No cabe duda de que, desde las primeras páginas, Rosario hace una opción política por los grupos marginados, los jamaiquinos explotados. En las páginas del libro, se puede apreciar que la autora es muy generosa al destacar los aportes de los afrocostarricenses, algo que, por supuesto, no negamos; sin embargo, es muy parca de reconocer el aporte de quienes detentaban el poder en todo el entramado histórico en cuestión. Reconoce que con la llegada de José Figueres al poder se inició el cambio en estos seres, marginados de todo, de las riquezas y de los derechos. En efecto, los afrocostarricenses comenzaron a tener una visibilidad más allá de sus brutales condiciones laborales, al ser reconocidos como seres humanos, e incluso, con el tiempo, como ciudadanos. Rosario se auxilia de otros autores para reconocerlo, pero no hace uso de sus 
propias palabras para resaltar la figura de Figueres, cuya gestión constituyó un verdadero hito en la historia de Costa Rica: existe un antes y un después de haber pasado por el poder. Sin embargo, el sesgo ideológico de la autora le impide reconocer sus aportes; más aún le impide tomar la distancia suficiente que necesita todo historiador para evaluar y juzgar con objetividad, fuera de todo prejuicio ideológico.

El entorno de El Caribe. Mientras leía el libro me hizo falta la contextualización con el Caribe insular, con los procesos similares, como fue el caso dominicano y la inmigración cocola a principios del siglo XX para trabajar en las plantaciones azucareras. El texto carece de algunas comparaciones en otros aspectos como, por ejemplo, las expresiones culturales. Lo extraño es que siendo Reina Rosario dominicana no hiciera comparaciones con expresiones culturales muy similares que se dan en las zonas cañeras, tales como el carnaval o la religiosidad popular. Estos rasgos son comunes en otras islas de la región. Podría decirse que en la narración ofrece algunas ideas comparativas con nuestro país, la República Dominicana, pero debo decir que extrañé estas referencias. Sentí la gran carencia con respecto a otras realidades caribeñas.

En conclusión, después de una revisión exhaustiva del libro, la obra sorprende por su amplísima indagación en distintas fuentes primarias, por la incorporación de fuentes orales y por una extensa y muy variada bibliografía consultada y utilizada como parte de la investigación; esto evidencia un rigor metodológico del más alto calibre. Además, los marcos teóricos y conceptuales fueron construidos con muchísimo detenimiento intelectual y fueron utilizados muy hábilmente para la argumentación base de la publicación. Sin duda, Identidades de la población de origen jamaiquino en el Caribe costarricense (segunda mitad del siglo XX) será en muy poco tiempo una de las obras de consulta obligatoria para todo estudio de la conformación y las identidades del Caribe.

\section{Referencias}

Rosario, Reina. (2015). Identidades de la población de origen jamaiquino en el Caribe costarricense (segunda mitad del siglo XX). Santo Domingo: Cocolo Editorial. 